\title{
Tobacco-Free Policy Support among Students in University Campuses
}

\author{
Siti Munira Yasin ${ }^{1}$, Aishah Zubillah², Mohamad Ikhsan Selamat ${ }^{1}$, Nurhuda Ismail ${ }^{1}$ \\ ${ }^{1}$ Public Health Medicine Department, ${ }^{2}$ Faculty of Medicine, \\ Universiti Teknologi Mara, Sungai Buloh, Selangor, Malaysia
}

smunira@uitm.edu.my; mohamadikhsan@uitm.edu.my, aishahzubillah135@gmail.com, yuda@uitm.edu.my Tel: +60192515325

\begin{abstract}
The purpose of this study was to determine support for various tobacco-free policies among students in public universities. This cross-sectional study was conducted among 406 students from three main campuses of a university in July 2018. Three hundred ninety-two students responded from three campuses in Selangor. There was a significant association between knowledge of secondhand smoke (SHS) and the types of tobacco-free policies. Students who perceived knowing the dangers of SHS also supported smoke-free cars and campus policy. In conclusion, knowledge of secondhand smoke, third-hand smoke, and tobacco-free policies should be enhanced.
\end{abstract}

Keywords: Tobacco-free campus, Second-hand smoker, students

eISSN: 2398-4287@ 2020. The Authors. Published for AMER ABRA cE-Bsby e-International Publishing House, Ltd., UK. This is an open access article under the CC BYNC-ND license (http://creativecommons.org/licenses/by-nc-nd/4.0/). Peer-review under responsibility of AMER (Association of Malaysian Environment-Behaviour Researchers), ABRA (Association of Behavioural Researchers on Asians) and cE-Bs (Centre for Environment-Behaviour Studies), Faculty of Architecture, Planning \& Surveying, UniversitiTeknologi MARA, Malaysia.

DOI: https://doi.org/10.21834/ebpj.v5i14.2246

\section{1,0 Introduction}

There were 5 million smokers in Malaysia classified as children or adolescents younger than 18 years old (Nik et al., 2017). By 2015, 1 in 10 Malaysians in the 13-17-year-old age groups were smokers. Researchers predicted earlier that if no interventions were to take place, mortality and morbidity from tobacco use would continue to increase by three folds worldwide in the next 20-25 years. Previous research revealed that a smoker who starts smoking before high school graduation tend to be actively smoking during their entire university years (Pan, Wang, Talaei, \& Hu, 2015). This factor was also reported as a cause for the increasing prevalence of secondhand smokers (SHS) in workplaces. Secondhand smoke is defined as not smoking but inhaling the smoke voluntarily and passively from the lit cigarette or the expiration of smokers. Secondhand smokers have detrimental health effects, almost similar to primary smokers. Another pressing issue is the loss of productivity, which was estimated to be USD5.6 billion yearly (Courtney, 2015). In Malaysia, the Global Adult Tobacco Survey in 2011 revealed that the prevalence of adults exposed to SHS in the workplace in the past 30 days was $39.8 \%$, while among nonsmokers was $33.9 \%$. Furthermore, $78.7 \%$ were exposed to SHS in bars/ nightclubs, $71 \%$ in restaurants, $84.9 \%$ in food eateries, $28.2 \%$ in government buildings, and $8.7 \%$ in healthcare facilities (Health, 2012; K. Lim et al., 2009). Thus, this awareness of the tobacco-free policy provides an opportunity to reduce future morbidity and mortality. (Pan, Wang, Talaei, \& Hu, 2015).

There are many different types of tobacco products available in the market, such as electronic cigarettes, shisha, and chewable tobacco. The consumption of smokeless tobacco with the use of electronic cigarettes had increased to was reported previously. This is worrisome given that almost one-fifth, 19.1\% among school-going children between 10-19 years of age (Perialathan et al., 2018), although a lot lesser prevalence among adults (3.2\%) between 18-24 years old (Nik et al., 2017). Findings also showed that vaping was actively being used as a means of quit smoking aid, although its effectiveness is questionable. While Shisha smoking can is common in educational institutions and gained popularity due to its sweet smell and flavor and perceived as less harmful and cheaper than conventional cigarette smoking (Baharudin et al., 2016). Nonetheless, the consumption of tobacco products depends upon the price of

eISSN: 2398-4287@ 2020. The Authors. Published for AMER ABRA cE-Bsby e-International Publishing House, Ltd., UK. This is an open access article under the CC BYNC-ND license (http://creativecommons.org/licenses/by-nc-nd/4.0/). Peer-review under responsibility of AMER (Association of Malaysian Environment-Behaviour Researchers), ABRA (Association of Behavioural Researchers on Asians) and cE-Bs (Centre for Environment-Behaviour Studies), Faculty of Architecture, Planning \& Surveying, UniversitiTeknologi MARA, Malaysia.

DOI: https://doi.org/10.21834/ebpj.v5i14.2246 
the tobacco product, disposable income of the consumer, demographic characteristics of the population, socio-economic status of the community, tobacco control intervention such as the promotion of tobacco products, knowledge, and information about the health effect of tobacco used (Al-Kubaisy et al., 2012, Liber, Ross, Omar, \& Chaloupka, 2015).

Malaysian governments have implemented various measures to counteract smoking in Malaysia. These initiatives were packed under MPOWER, as recommended by the Framework Convention of Tobacco Control (FCTF) Malaysia has engaged in since 2005 (Pei et al., 2020). Among the initiatives include imposing higher prices of cigarettes, discourage new users from taking up a cigarette, encouraging existing users to quit, helping former users to stay quit, and preventing occasional smokers from turning into regular smokers. Another initiative was to reduce the consumption of tobacco products among those who continue to use tobacco after a price hike. Besides, increasing in tobacco excise taxes would result in a decline of tobacco use, thus, encouraging current tobacco users to quit, reducing the number of cigarettes consumed by existing users and reducing the initiation and uptake of tobacco use among young people with more significant impact (Pei et al., 2020).

Another effective intervention is to create a smoke-free environment, either in workplaces or public places. One good strategy to target youth is to enforce smoke-free policies within the campus, and the first step is to implement a tobacco-free plan. The Tobaccofree campus policy comprised of protection from secondhand smoke, a ban on the use of any type of tobacco on campus, which aims to protect from exposure to tobacco use. Thus, it is essential to prevent students from initiating smoking, helping ex-smokers stay off cigarettes, and helping smokers to quit. There are many other benefits of this comprehensive policy including the ability to provide a healthier and cleaner environment and reduce the risk of fire both indoors and outdoors (Rath et al., 2019).

Although in western nations, the majority of Universities are struggling to implement a 100\% tobacco-free, and many are with success stories, in Malaysia, this receives little attention and is relatively new. Those previous studies identified some facilitators of such policy, including creating a committee within the campus, establishing venues to foster student debate, and reaching out to stakeholders inside the campus. While barriers include lack of involvement among students, faculties and administrative staff, and insufficient resources for implementation (Fallin-Bennett, Roditis, \& Glantz, 2017).

The focus of this article was to focus on enacting a tobacco-free policy in a large public university. Before policy implementation, smoking on campus were prohibited in all indoor public spaces. We report findings after two years of implementing this policy in one college, which would be adopted on another two campuses. Our research aims to identify the following: 1) to assess awareness of SHS among students; 2) to identify areas of policy support among students who knew about SHS; 3) to identify compliance with tobacco-free policy among different campuses.

\subsection{Methods}

In 2016, a Tobacco-free Initiative in Campus was formed. The campus initiatives were establishing as a comprehensive program, including technical assistance to smokers who wanted to quit smoking (i.e., materials, webinars, quit smoking service, signages). To build awareness of this program, team members engaged stakeholders, attended conferences, and visited individual campuses to highlight the components of the program and encourage the submission of applications. In this study, we took three main campuses of a large public university in Selangor as the respondence. The three campuses housed approximately 100,000 students from various courses and years of study. The distances from each campus were $20 \mathrm{~km}$ each, and students selected stayed on the campus. Campus A has implemented tobacco-free policies since 2016, whereas campus $B$ and $C$ are awaiting implementation.

A cross-sectional study was carried out between March 2018 until February 2019. All eligible respondents from the three campuses were invited to participate in this study. Inclusion criteria were Bumiputera, aged 18 years old and above, able to understand the Malay language. Postgraduate students were excluded. Sampling involved multistage random sampling and quota sampling of all faculties on the three campuses. The first stage involved a random selection of faculties based on clusters for each college. Next, participants were selected based on numbers by years, by quota sampling. The quotas were based on the number of students from each campus. Participation was voluntary, and all participants were provided written consent. A standardized, self- administered and validated questionnaire was distributed to all participants after the briefing. The survey took approximately 5-10 minutes to complete. The Research Ethic Committee approved the study design, protocols, procedures, and informed consent of the university involved. The minimum sample size required was $\mathrm{N}=166$, based on $95 \% \mathrm{Cl}$, alpha 0.05 , and calculating $20 \%$ attrition using would be 199 participants, based on studies by Braverman et al. (2017), (Braverman, Hoogesteger, Johnson, \& Aarø, 2017)

\subsection{Participants: \\ Research Tools}

The measures for this study were developed based on group discussions with students held during lecture classes. All respondents completed a questionnaire about sociodemographic characteristics, smoking history, awareness on tobacco-free, and support for tobacco-free. The surveys took 15 minutes to complete.

The questionnaires comprised of multiple-choice questions and some binary (yes/no) questions.

There were three sections of the questionnaire.

Part A. Sociodemographic characteristics and smoking history: Sociodemographic characteristics included gender (male or female), age, year of study (1-5) and the various races in Malaysia, education attainment, lifestyle behaviours.

Part B. Assessing the perceived knowledge towards smoking and exposure to tobacco smoke among smokers and nonsmokers.

Part C: Assess the approval of tobacco-free policy for campuses and other places, and other sites. These include support for smokefree cars and smoke-free homes. 
Part B and C were based on our previously validated questionnaires used in the university population (Yasin et al., 2016; Yasin et al., 2013).

\subsection{Statistical Analysis:}

SPSS version 26.0 was used to analyze the data in this study. Data analyzed were displayed as frequencies, percentages, maximum value, minimum value, means, modes, medians, and standard deviations. The analysis employed includes $\mathrm{Chi}$-squared tests and logistic regressions. Multiple logistic regression was used for the third part of analysis involving students who knew SHS. Results were displayed as odds ratios $(\mathrm{OR})$ and $95 \%$ confidence intervals $(95 \% \mathrm{Cl})$, with alpha 0.05 being taken as the level of significance.

\subsection{Results}

Out of 406 students that were approached, 392 students $(94.65 \%)$ responded. The majority of students were in the age group of 21-23 years old $(76 \%, \mathrm{~N}=298)$. Based on the overall data, $5.1 \%$ of respondents from the three campuses exercised more than five times a week, and $16.8 \%$ were physically inactive; and had never exercised before on campus. The other sociodemographic characteristics were in Table 1. A chi-squared test was applied to explore the association between secondhand smokers and selected variables (Table 2). About $81.9 \%$ (321 students) of were aware of the policy in campus and had shown support for the tobacco-free policy in Campus $A$, as compared to students from the other 2 campuses. $(p<0.05)$. Bonferroni post-hoc test indicates that Campus $B$ showed significantly higher mean (SD) numbers of secondhand smoker [1.25(0.44)], as compared to Campus A [1.05(0.23)] The difference between Campus B and Campus C was not statistically significant. Besides that, Campus A showed a significantly higher mean (SD) of secondhand smokers. They agreed on the importance of having a smoke-free campus [1.27(0.61)] than Campus B. Figure 1 and 2 diagrams of support for the policies from the campuses.

Table 1: Demographic characteristic

\begin{tabular}{|c|c|c|}
\hline Variables & $\mathrm{N}=392$ & Frequency (\%) \\
\hline \multicolumn{3}{|l|}{ Age } \\
\hline $18-20$ & 56 & 14.3 \\
\hline $21-23$ & 298 & 76.0 \\
\hline $24-26$ & 38 & 9.7 \\
\hline \multicolumn{3}{|l|}{ Gender } \\
\hline Male & 78 & 19.9 \\
\hline Female & 314 & 80.1 \\
\hline \multicolumn{3}{|l|}{ Ethnicity } \\
\hline Malay & 382 & 97.4 \\
\hline Chinese & 1 & 0.3 \\
\hline Indian & 0 & 0.0 \\
\hline Sabahan & 5 & 1.3 \\
\hline Sarawakian & 4 & 1.0 \\
\hline \multicolumn{3}{|l|}{ Highest education } \\
\hline SRP/PMR & 1 & 0.3 \\
\hline SPM & 10 & 2.6 \\
\hline STPM/Matriculation/Diploma/A-level & 178 & 45.4 \\
\hline Degree & 199 & 50.8 \\
\hline Master & 4 & 1.0 \\
\hline PHD/Sub-speciality & 0 & 0 \\
\hline \multicolumn{3}{|l|}{ Exercise in a week } \\
\hline Never & 66 & 16.8 \\
\hline 1-2 times & 240 & 61.2 \\
\hline 3-4 times & 66 & 16.8 \\
\hline$>5$ times & 20 & 5.1 \\
\hline \multicolumn{3}{|c|}{ Serving of fruits and vegetables you eat in a week } \\
\hline $0-5$ & 263 & 67.1 \\
\hline $6-10$ & 97 & 24.7 \\
\hline $11-14$ & 20 & 5.1 \\
\hline$>15$ & 12 & 3.1 \\
\hline \multicolumn{3}{|l|}{ Mother/father smoked } \\
\hline No & 241 & 61.5 \\
\hline Both & 3 & 0.8 \\
\hline Only father & 147 & 37.5 \\
\hline Only mother & 1 & 0.3 \\
\hline \multicolumn{3}{|c|}{ If your friend offering cigarettes to you, would you try? } \\
\hline Surely no & 363 & 92.6 \\
\hline Maybe no & 19 & 4.8 \\
\hline Maybe yes & 7 & 1.8 \\
\hline Surely yes & 3 & 0.8 \\
\hline \multicolumn{3}{|c|}{ Knowledge on rules and regulation of smoking in your campus } \\
\hline Yes & 375 & 95.7 \\
\hline
\end{tabular}




\begin{tabular}{|lcc|}
\hline No & 17 & 4.3 \\
Knowledge on second-hand smoker/secondary smoker? & & 83.2 \\
Yes & 326 & 16.8 \\
No & 66 & \\
Ynowledge on third-hand smoker/tertiary smoker? & & 63.3 \\
No & 248 & 36.7 \\
\hline
\end{tabular}

Table 2. Awareness on tobacco-free policies among students

\begin{tabular}{|c|c|c|c|}
\hline \multirow[t]{2}{*}{ VARIABLES } & \multicolumn{2}{|c|}{$\begin{array}{c}\text { SHS knowledge } \\
(\mathrm{N}=392)\end{array}$} & \multirow[t]{2}{*}{$\begin{array}{l}\text { P-VALUES } \\
(<0.05)\end{array}$} \\
\hline & Yes & No & \\
\hline \multicolumn{4}{|c|}{$\begin{array}{l}\text { Are you aware of the tobacco-free policies } \\
\text { at your campus? }\end{array}$} \\
\hline Yes & $297(76.0 \%)$ & $53(13.6 \%)$ & \\
\hline No & $28(7.2 \%))$ & $13(3.3 \%)$ & 0.007 \\
\hline \multicolumn{4}{|c|}{$\begin{array}{l}\text { In your opinion, should a smoke-free car } \\
\text { be enforced? }\end{array}$} \\
\hline Yes & $306(78.1 \%)$ & $57(14.5 \%)$ & 0.034 \\
\hline No & $20(5.1 \%)$ & $9(2.3 \%)$ & \\
\hline \multicolumn{4}{|c|}{$\begin{array}{l}\text { In your opinion, should a smoke-free house } \\
\text { should be enforced? }\end{array}$} \\
\hline Yes & $281(71.7 \%)$ & $49(12.5 \%)$ & 0.015 \\
\hline No & $45(11.5 \%)$ & $17(4.3 \%)$ & \\
\hline \multicolumn{4}{|c|}{$\begin{array}{l}\text { Would you like to join as a peer support in } \\
\text { assisting other smokers to quit? }\end{array}$} \\
\hline Yes & $306(78.1 \%)$ & $57(14.5 \%)$ & 0.034 \\
\hline No & $20(5.1 \%)$ & $9(2.3 \%)$ & \\
\hline \multicolumn{4}{|c|}{$\begin{array}{l}\text { Does breathing other people's smoke pose health } \\
\text { risks to surrounding people? }\end{array}$} \\
\hline Yes & $324(82.7 \%)$ & $63(16.1 \%)$ & \\
\hline No & $0(0 \%)$ & $2(0.5 \%)$ & 0.034 \\
\hline Not sure & $2(0.5 \%)$ & $1(0.3 \%)$ & \\
\hline \multicolumn{4}{|c|}{ Should smoking be banned in public areas? } \\
\hline Yes & $289(73.7 \%)$ & $50(12.8 \%)$ & \\
\hline No & $11(3.2 \%)$ & $6(1.3 \%)$ & 0.020 \\
\hline Not sure & $26(6.6 \%)$ & $11(16.8 \%)$ & \\
\hline \multicolumn{4}{|c|}{ Will you support tobacco-free policies in various areas? } \\
\hline Yes & $315(80.4 \%)$ & $56(14.3 \%)$ & \\
\hline No & $6(1.5 \%)$ & $4(1 \%)$ & 0.000 \\
\hline \multicolumn{4}{|c|}{$\begin{array}{l}\text { How important is it to you to have a } \\
\text { Tobacco free campus? }\end{array}$} \\
\hline Not important & $11(2.8 \%)$ & $7(1.8 \%)$ & 0.009 \\
\hline Less important & $26(6.6 \%)$ & $4(1.0 \%)$ & \\
\hline Important & $91(23.2 \%)$ & $26(6.6 \%)$ & \\
\hline Very important & $197(50.3 \%)$ & $28(7.1 \%)$ & \\
\hline
\end{tabular}

Table 3 displays the logistic regression for support on tobacco-free policies among students with knowledge on SHS. This was significantly observed among those who would prefer smoke-free cars up to two folds. Students who knew secondhand smokers were also twice as likely to agree to join in a peer support group to assist smokers compared to those without adequate knowledge. Lastly, those students would also significantly support a tobacco-free campus as compared to those without such knowledge.

Figure 1-3 below shows the support for campus policies and typical hotspot identified areas within the campus. Overall, support was highest among students living in Campus $\mathrm{A}$ as compared to other colleges. 
Table 3: Analysis of results for support towards policy for those with knowledge on second hand smoke

\begin{tabular}{|c|c|c|c|c|c|}
\hline \multirow{3}{*}{$\begin{array}{l}\text { In your opinion, should a smoke-free car } \\
\text { Should enforced? }\end{array}$} & \multicolumn{3}{|c|}{ Non-adjusted } & \multicolumn{2}{|l|}{ Adjusted } \\
\hline & $\mathrm{N}(\%)$ & OR $(95 \% \mathrm{Cl})$ & $\mathbf{P}$ & OR $(95 \% \mathrm{Cl})$ & $\mathbf{P}$ \\
\hline & & & & & \\
\hline No & 20 & Ref & & Ref & \\
\hline Yes & $306(93.8)$ & $5.21(1.71-15.88)$ & $0.004^{*}$ & $2.86(1.28-6.39)$ & $0.038^{*}$ \\
\hline \multicolumn{6}{|c|}{$\begin{array}{l}\text { In your opinion, does a smoke-free house } \\
\text { be enforced? }\end{array}$} \\
\hline No & 45 & Ref & & Ref & \\
\hline Yes & 281 & $5.94(1.50-23.60)$ & $0.011^{*}$ & $2.56(0.99-6.61)$ & 0.053 \\
\hline \multicolumn{6}{|c|}{$\begin{array}{l}\text { Would you like to join as a peer support in } \\
\text { assisting other smokers to quit? }\end{array}$} \\
\hline No & 20 & Ref & & Ref & \\
\hline Yes & 306 & $5.08(1.76-14.61)$ & $0.003^{*}$ & $2.43(1.21-4.89)$ & $0.013^{*}$ \\
\hline \multicolumn{6}{|c|}{$\begin{array}{l}\text { Do you think a smoker need to ask for } \\
\text { permission before smoking near you? }\end{array}$} \\
\hline $\begin{array}{l}\text { No } \\
\text { Yes }\end{array}$ & $\begin{array}{l}26 \\
300\end{array}$ & $\begin{array}{c}\text { Ref } \\
0.000\end{array}$ & $\begin{array}{l}0.002^{*} \\
0.000^{*}\end{array}$ & $\begin{array}{c}\operatorname{Ref} \\
1.07(0.214-5.31)\end{array}$ & $\begin{array}{l}0.602 \\
0.939\end{array}$ \\
\hline \multicolumn{6}{|c|}{ Should smoking be banned in public areas? } \\
\hline No & 11 & Ref & 0.178 & Ref & 0.046 \\
\hline Yes & 289 & $4.80(0.80-28.81)$ & 0.086 & $2.56(0.66-9.85)$ & 0.173 \\
\hline \multicolumn{6}{|c|}{$\begin{array}{l}\text { Will you support non-smoking policies in } \\
\text { various areas? }\end{array}$} \\
\hline No & 6 & Ref & 0.24 & Ref & 0.002 \\
\hline Yes & 315 & NAD & 0.99 & $3.0(30.59-15.55)$ & 0.185 \\
\hline \multicolumn{6}{|c|}{$\begin{array}{l}\text { How important is it to you to have a } \\
\text { Tobacco free campus? }\end{array}$} \\
\hline Not Important & 11 & Ref & $0.02^{*}$ & Ref & 0.020 \\
\hline Less important & 26 & $3.42(1.12-10.42)$ & 0.03 & $2.92(1.32-6.46)$ & $0.008^{*}$ \\
\hline Important & 91 & $33.67(1.87-607.92)$ & $0.02^{*}$ & $11.49(0.839-157.56)$ & 0.067 \\
\hline Very important & 197 & $7.76(0.37-163.40)$ & 0.19 & NAD & 1.000 \\
\hline
\end{tabular}

Adjusted for other factors (tobacco use, secondhand smoker and influence of cigarette smoke) and sociodemographic characteristics

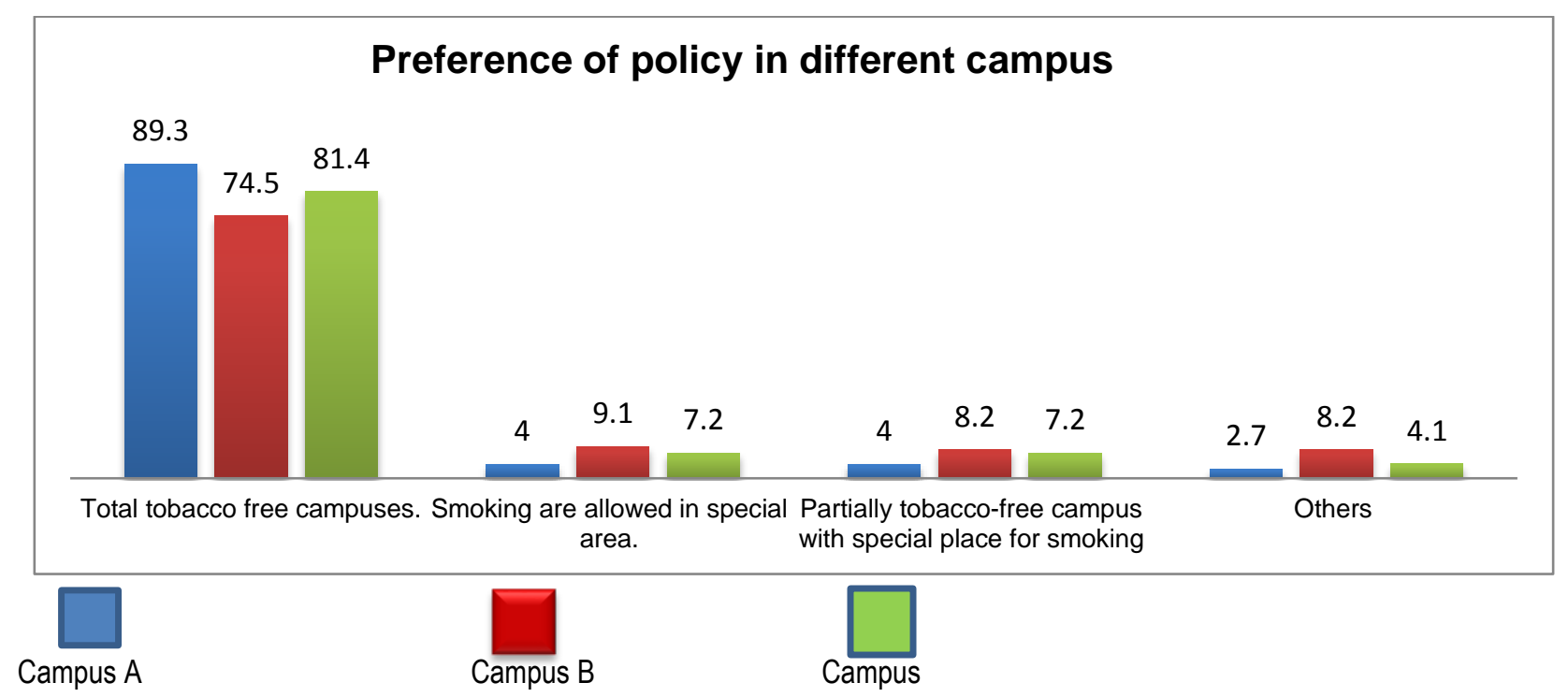

Figure 1: Preference of the different type of policy in three campuses 


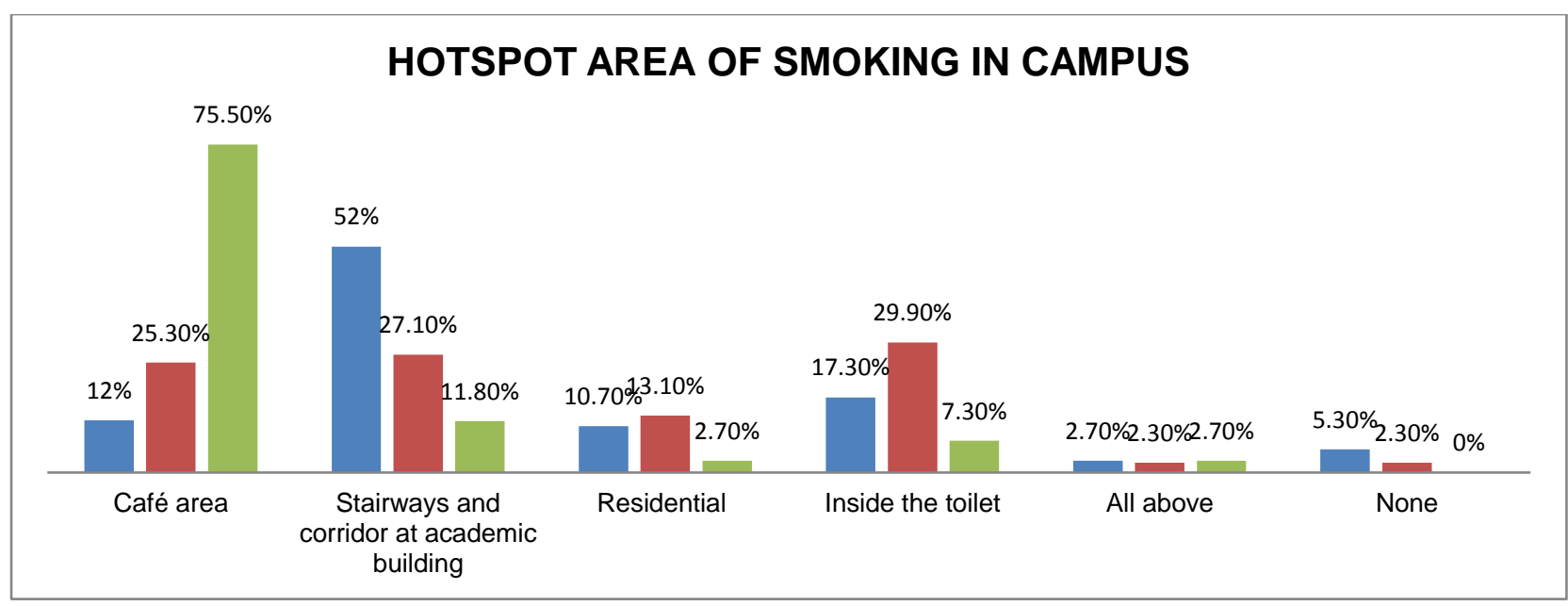

Figure 2: The hostspot area of smoking in three different campuses.

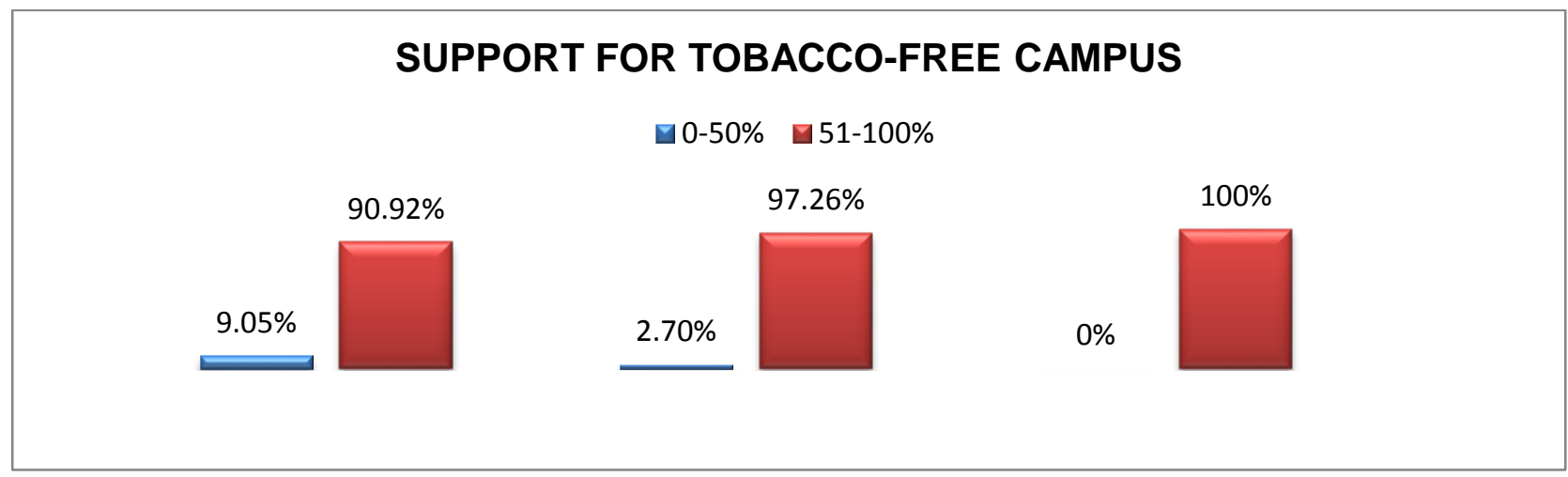

Red: Yes; Blue: No

Figure 3: The scale of $0-100 \%$ for support for a tobacco-free campus.

\subsection{Discussion}

With a tobacco-free policy in place, over $89 \%$ of support were received for a tobacco-free campus policy on Campus A. The support for the other two campuses were lesser. Samples from campus B and C had substantially overestimated the support. The result was most probably due to female predominance support, as most smokers in Malaysia were among males, both in adults and adolescents (Lamin, Othman, \& Othman, 2014; H. K. Lim et al., 2013). Based on sociodemographic data from the three campuses, $61.5 \%$, $\mathrm{N}=241$ of the parents were nonsmokers, while the rest had either both or one of them who were smokes. Knowing the smoking history of parents may point out the susceptibility of the youth themselves to engage in smoking (Hock et al., 2013). Nonetheless, our findings do not support such a hypothesis. Further research may investigate the issue of gender roles further and the possibility of causal pathways.

The survey revealed distinctive differences of support between campus $A(100 \%)$ as compared to the other two campuses without such policies. The locations of smoking hotspots identified evidenced the effectiveness. However, it is noteworthy, that the patterns seen in stairways and corridors might predict that support for the policy existed, and smokers are afraid to smoke in open spaces. Nonetheless, as of restaurants, we still observed this phenomenon, which clearly showed a lack of enforcement. However, the exposures outside the campus may be more extensive, especially outside the main gate, where the policy stated that smoking could only be allowed 50 meters from the entrance. These similar findings have also been reported by other university campuses worldwide (Braverman, Hoogesteger, \& Johnson, 2015).

There is little published research looking into support for smoke-free homes and smoke-free cars among adolescents and youth. Our study revealed excellent support of above $70 \%$ in cars and homes. The result is slightly lower than reported in the United States in both locations of above $80 \%$ in households and $71.5 \%$ for vehicles, (Parks, Kingsbury, Boyle, \& Evered, 2018). In our study, the support for smoke-free cars was significantly higher among those with knowledge on SHS. Youth tend to misinterpret it as less harmful and be the victim of SHS exposures at home (Barnoya \& Glantz, 2005). Those with SHS awareness also tend to be more concerned about their smoking colleagues and would like to offer assistance to protect themselves. This might also mean that they perceived higher responsibility towards ensuring clean air for all. Thus, our findings clearly showed the importance of providing youth with adequate knowledge of SHS's health effects, as this knowledge translates into policy. 
Nonetheless, in most instances, education does not necessarily predict action, although it was proven to be associated with a better attitude and cultural change (Zhang, Martinez-Donate, \& Rhoads, 2015). As for third-hand smoke, the poor knowledge of this instance is a significant concern. However, it can be an essential component to gain additional support if expertise on this issue is intensified.

With regards to implementation, some respondents were still unsure whether they should support the total tobacco ban if the policy were implemented on each campus. As other researchers discussed this (Braverman et al., 2015), if the campus stakeholders perceive that SHS may affect them, there would be a strong demand and lower opposition from various parties. Indeed, if we were to provide such support surveys, this might be an excellent way to gain support from campus administrators. The sizable backing of this study was much higher than the support obtained from other studies. We strongly believe that this was due to prior acceptance of outdoor smoking prohibition in public places and various other no smoking prohibition signages throughout campus. This affirmative acceptance will point out that if the policy were to be implemented on campus not yet tobacco-free, students' support would be excellent. In university settings, however, in reality, there are many other possible oppositions, such as administrators, workers, educators, external contractors, that needs to be tackled. Hence, further exploration of this issue among various groups is warranted (Braverman et al., 2015). Moreover, active campaigns, seminars or talk on the importance of policy should be intensified to ensure its success later.

The most significant limitation of this study was that this was a self-reported study and are subjected to bias. Some respondents may underreport smoking habit and were not excluded from this study. The initial prevalence identified by $3.2 \%$ was way lower than the global, national prevalence of smoking in Malaysia of $23 \%$ (K. H. Lim et al., 2018). However, since most of the respondents were female, and the local female prevalence was lower than the male prevalence, we assume our prevalence was correct. Secondly, the race in this study was only among Malay race and natives, and not from other races, hence, other traces within a campus should be included in future studies. Thirdly, due to the nature of cross-sectional study design, no inferences can be obtained, as it covers only one point of time. For instance, the findings' predictive nature as a basis for policy support were inconclusive.

This study had several strengths. First, the policy was examined in the context of a policy that had already existed for campus A, and this was inherently compared to the other two campuses. Hence, the results less hypothetical, as compared to our previous study among staff. Secondly, the sampling frame and the response was excellent, higher than most reviews.

\subsection{Recommendations and Conclusions}

In conclusion, continuous education on the danger of being a secondhand smoker and third-hand smoker is required to increase awareness and understand the health risks due to tobacco smoke exposure among students. Consequently, this will increase the number of support for tobacco-free policies and reduce tobacco intake. Nonetheless, although implementation was initiated, notably, exposure to tobacco smoke has not been totally eliminated. More efforts of strict enforcement and monitoring of tobacco use should routinely be made to ensure sustainability of such tobacco free policies. Further research is also required to promote tobacco-free policies among various groups and effective methods to enforce such policies. Lastly, innovations in combating this global issue are much warranted, especially ways on how to eliminate hotspot smoking zones within the campus.

\section{Acknowledgement}

The authors would like to thank the participants and the top facility administrators for granting permission to conduct this study. Special acknowledgment goes to medical students who assisted in data collection.

\section{References}

Al-Kubaisy, W., Abdullah, N. N., Al-Nuaimy, H., Kahn, S. M., Halawany, G., \& Kurdy, S. (2012). Factors associated with smoking behaviour among university students in Syria. Procedia-Social and Behavioral Sciences, 38, 59-65

Baharudin, M. I., Al Kubaisy, W., Norden, N., Lairy, R., Yazid, N. A., Azlan, N. L. M., . . Bannur, Z. (2016). Prevalence of nicotine dependence among youth smokers (Cigarette and Shisha) in Malaysia. GSTF Journal of Nursing and Healthcare, 3, 39-47.

Barnoya, J., \& Glantz, S. A. (2005). Cardiovascular effects of secondhand smoke: nearly as large as smoking. Circulation, 111(20), 2684-2698.

Braverman, M. T., Hoogesteger, L. A., \& Johnson, J. A. (2015). Predictors of support among students, faculty and staff for a smoke-free university campus. Preventive medicine, $71,114-120$.

Braverman, M. T., Hoogesteger, L. A., Johnson, J. A., \& Aarø, L. E. (2017). Supportive of a smoke-free campus but opposed to a 100\% tobacco-free campus: Identification of predictors among university students, faculty, and staff. Preventive medicine, 94, 20-26.

Courtney, R. (2015). The Health Consequences of Smoking-50 Years of Progress: A Report of the Surgeon General, 2014 Us Department of Health and Human Services Atlanta, GA: Department of Health and Human Services, Centers for Disease Control and Prevention, National Center for Chronic Disease Prevention and Health Promotion, Office on Smoking and Health, 20141081 pp. Online (grey literature): http://www. surgeongeneral. gov/library/reports/50-years-of-progress. Drug and Alcohol Review, 34(6), 694-695.

Fallin-Bennett, A., Roditis, M., \& Glantz, S. A. (2017). The carrot and the stick? Strategies to improve compliance with college campus tobacco policies. Journal of American College Health, 65(2), 122-130 
Health, I. o. P. (2012). Report of the Global Adult Tobacco Survey (GATS) Malaysia 2011. In: Ministry of Health Malaysia Putrajaya.

Hock, L. K., Ghazali, S. M., Cheong, K. C., Kuay, L. K., Li, L. H., Ying, C. Y., . . Yen, Y. L. (2013). Correlates of susceptibility to smoking among secondary school students in Kota Tinggi District, Johor, Malaysia. Asian Pacific Journal of Cancer Prevention, 14(11), 6971-6978.

Lamin, R. A. C., Othman, N., \& Othman, C. N. (2014). Effect of smoking behavior on nicotine dependence level among adolescents. Procedia-Social and Behavioral Sciences, 153, 189-198.

Liber, A. C., Ross, H., Omar, M., \& Chaloupka, F. J. (2015). The impact of the Malaysian minimum cigarette price law: findings from the ITC Malaysia Survey. Tobacco control, 24(Suppl 3), iiï3-iii87.

Lim, H. K., Ghazali, S. M., Kee, C. C., Lim, K. K., Chan, Y. Y., Teh, H. C., . . Mohamad, M. H. N. (2013). Epidemiology of smoking among Malaysian adult males: prevalence and associated factors. BMC public health, 13(1), 8.

Lim, K., Sumarni, M., Amal, N., Hanjeet, K., Wan Rozita, W., \& Norhamimah, A. (2009). Tobacco use, knowledge and attitude among Malaysians age 18 and above. Trop Biomed, 26(1), 92-99.

Lim, K. H., Teh, C. H., Pan, S., Ling, M. Y., Yusoff, M. F., Ghazali, S. M., . . . Lim, H. L. (2018). Prevalence and factors associated with smoking among adults in Malaysia: findings from the National Health and morbidity survey (NHMS) 2015. Tobacco induced diseases, 16.

Nik, J. A. R. M. H., Mohamed, M. K., Ab Rahman, N. S., Draman, S., Yusoff, M. F. M., \& Aris, T. (2017). National E-cigarette Survey (NECS) 2016 in Malaysia-Method and population characteristics. Med J Malaysia, 72, A144.

Pan, A., Wang, Y., Talaei, M., \& Hu, F. B. (2015). Relation of smoking with total mortality and cardiovascular events among patients with diabetes mellitus: a meta-analysis and systematic review. Circulation, 132(19), 1795-1804

Parks, M. J., Kingsbury, J. H., Boyle, R. G., \& Evered, S. (2018). Peer Reviewed: Smoke-Free Rules in Homes and Cars Among Smokers and Nonsmokers in Minnesota. Preventing chronic disease, 15.

Pei, H. P., Hock, L. K., Yusoff, M. F. M., Huey, T. C., Mohamad, S., Ghazali, L. H. L., . . Hui, L. J. (2020). Implementation of MPOWER Approach for Tobacco Control in Malaysia: Findings from the Global Adult Tobacco Survey (GATs).

Perialathan, K., Rahman, A. B., Lim, K. H., Adon, Y., Ahmad, A., Juatan, N., \& Jaafar, N. (2018). Prevalence and associated factors of ever use of electronic cigarettes: Findings from a hospitals and health clinics study based in Malaysia. Tobacco induced diseases, 16.

Rath, J. M., Pitzer, L., Carnegie, B., Shinaba, M., Vallone, D., Parks, I., .. . Hair, E. C. (2019). Building capacity to implement tobacco-free policies in college and university settings with underserved populations. Tobacco Prevention \& Cessation, 5.

Yasin, S. M., Isa, M. R., Fadzil, M. A., Zamhuri, M. I., Selamat, M. I., Ruzlin, A. N. M., . . Majeed, A. B. A. (2016). Support for a campus tobacco-free policy among nonsmokers: Findings from a developing Country. Asian Pac J Cancer Prev, 17, 275-280.

Yasin, S. M., Ismail, N., Noor, N. M., Azman, M. S. M., Taib, H., Jusop, J. M., \& Salaudin, N. A. (2013). Gender differences in responses towards anti-smoking messages and policy implementation among future doctors in Malaysia. Asian Pacific Journal of Cancer Prevention, 14(1), 303-308.

Zhang, X., Martinez-Donate, A., \& Rhoads, N. (2015). Parental Practices and Attitudes Related to Smoke-Free Rules in Homes, Cars, and Outdoor Playgrounds in US Households With Underage Children and Smokers, 2010-2011. Preventing chronic disease, 12, E96-E96. 